\title{
Front Matter: Volume 10809
}

, "Front Matter: Volume 10809," Proc. SPIE 10809, International Conference on Extreme Ultraviolet Lithography 2018, 1080901 (12 November 2018); doi: 10.1117/12.2517863

SPIE Event: SPIE Photomask Technology + Extreme Ultraviolet Lithography, 2018, SPIE. Monterey, California, United States 


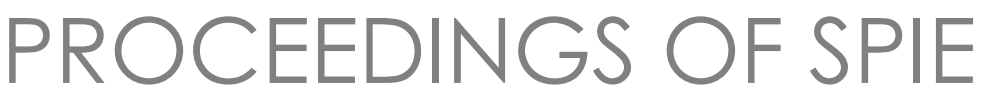

\title{
International Conference on Extreme Ultraviolet Lithography 2018
}

\author{
Kurt G. Ronse \\ Eric Hendrickx \\ Patrick P. Naulleau \\ Paolo A. Gargini \\ Toshiro Itani \\ Editors \\ Sponsored by \\ SPIE \\ Cosponsored by \\ Eureka \\ EIDEC (Japan) \\ IMEC (Belgium) \\ Published by \\ SPIE
}

17-20 September 2018

Monterey, California, United States 
The papers in this volume were part of the technical conference cited on the cover and title page. Papers were selected and subject to review by the editors and conference program committee. Some conference presentations may not be available for publication. Additional papers and presentation recordings may be available online in the SPIE Digital Library at SPIEDigitalLibrary.org.

The papers reflect the work and thoughts of the authors and are published herein as submitted. The publisher is not responsible for the validity of the information or for any outcomes resulting from reliance thereon.

Please use the following format to cite material from these proceedings:

Author(s), "Title of Paper," in International Conference on Extreme Ultraviolet Lithography 2018, edited by Kurt G. Ronse, Eric Hendrickx, Patrick P. Naulleau, Paolo A. Gargini, Toshiro Itani, Proceedings of SPIE Vol. 10809 (SPIE, Bellingham, WA, 2018) Seven-digit Article CID Number.

ISSN: 0277-786X

ISSN: 1996-756X (electronic)

ISBN: 9781510622135

ISBN: 9781510622142 (electronic)

Published by

SPIE

P.O. Box 10, Bellingham, Washington 98227-0010 USA

Telephone +1 3606763290 (Pacific Time) · Fax +1 3606471445

SPIE.org

Copyright @ 2018, Society of Photo-Optical Instrumentation Engineers.

Copying of material in this book for internal or personal use, or for the internal or personal use of specific clients, beyond the fair use provisions granted by the U.S. Copyright Law is authorized by SPIE subject to payment of copying fees. The Transactional Reporting Service base fee for this volume is $\$ 18.00$ per article (or portion thereof), which should be paid directly to the Copyright Clearance Center (CCC), 222 Rosewood Drive, Danvers, MA 01923. Payment may also be made electronically through CCC Online at copyright.com. Other copying for republication, resale, advertising or promotion, or any form of systematic or multiple reproduction of any material in this book is prohibited except with permission in writing from the publisher. The CCC fee code is 0277$786 \mathrm{X} / 18 / \$ 18.00$.

Printed in the United States of America.

Publication of record for individual papers is online in the SPIE Digital Library.

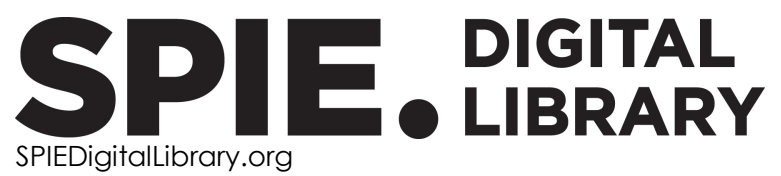

Paper Numbering: Proceedings of SPIE follow an e-First publication model. A unique citation identifier (CID) number is assigned to each article at the time of publication. Utilization of CIDs allows articles to be fully citable as soon as they are published online, and connects the same identifier to all online and print versions of the publication. SPIE uses a seven-digit CID article numbering system structured as follows:

- The first five digits correspond to the SPIE volume number.

- The last two digits indicate publication order within the volume using a Base 36 numbering system employing both numerals and letters. These two-number sets start with 00, 01, 02, 03, 04, 05, 06, 07, 08, 09, OA, OB ... 0Z, followed by 10-1Z, 20-2Z, etc. The CID Number appears on each page of the manuscript. 


\title{
Contents
}

\author{
vii Authors \\ ix Conference Committee \\ xi Introduction
}

PLENARY SESSION

1080902 Accelerate lithography improvement for high performance computing (Plenary Paper) [10809-1]

1080903 Current challenges and opportunities for EUV lithography (Plenary Paper)

[10809-2]

EUV SCANNER AND SOURCE

1080904 EUV industrialization high volume manufacturing with NXE3400B (Invited Paper) [10809-3]

1080905 NXE:3400B imaging performance assessed from a customer perspective [10809-4]

1080907 Accelerator-based compact extreme ultraviolet (EUV) sources for lithography [10809-6]

EUV PROCESS CONTROL

1080909 EUV stochastic defect monitoring with advanced broadband optical wafer inspection and e-beam review systems (Invited Paper) [10809-8]

10809 OA Non-Gaussian CD distribution characterization for DRAM application in EUV lithography [10809-9]

10809 OB Measurement and modeling of diffusion characteristics in EUV resist [10809-10]

10809 OC Massive CD metrology for EUV failure characterization and EPE metrology [10809-11]

EUV MASK BLANKS: JOINT SESSION WITH CONFERENCES 10809 AND 10810

10809 OF Ion beam processing for critical EUV photomask process steps: mask blank deposition and photomask absorber etch [10809-14] 
EUV MASK AND IMAGING: JOINT SESSION WITH CONFERENCES 10809 AND 10810

10809 OM Optimization and stability of CD variability in pitch $40 \mathrm{~nm}$ contact holes on NXE:3300 [10809-20]

10809 ON EUV pupil optimization for 32nm pitch logic structures [10809-66]

$1080900 \quad$ Rapid image-based pupil plane characterization for EUV lithography systems [10809-22]

EUV PELLICLE AND METROLOGY: JOINT SESSION WITH CONFERENCES 10809 AND 10810

10809 OR Development of full-size EUV pellicle with thermal emission layer coating [10809-25]

10809 OT EUV mask characterization with actinic scatterometry [10809-27]

\section{EUV MATERIALS II}

10809 OU State-of-the-art of EUV materials for N5 logic and DRAM applications (Invited Paper) [10809-28]

10809 OV Using resonant soft $x$-ray scattering to image patterns on undeveloped resists [10809-29]

10809 OX New resist and underlayer approaches toward EUV lithography [10809-31]

\section{PATTERNING}

1080914 Integration via 3rd dimension: 3D power scaling (Invited Paper) [10809-38]

1080916 Study of resist hardmask interaction through surface activation layers [10809-40]

POSTER SESSION: EUV MASK

1080919 Optimization of absorber and multilayer in EUV mask for 1D and 2D patterns [10809-43]

10809 1A Holographic masks for computational proximity lithography with EUV radiation [10809-44]

10809 1E A tool for full area inband EUV transmission mapping of EUV pellicles [10809-49]

$108091 \mathrm{G} \quad$ Pattern degradation with larger particles on EUV pellicle [10809-51]

10809 1H Defect avoidance for extreme ultraviolet mask defects using intentional pattern deformation [10809-52]

iv 
1080911 AIMERTM: full reticle area, scanner-effective EUV mapping reflectometry [10809-53]

POSTER SESSION: EUV SOURCE

$108091 \mathrm{~L} \quad$ NXE:3400B EUV source performance in the field, readiness for HVM and power scaling beyond 250W [10809-56]

$108091 \mathrm{M} \quad$ Key components development progress of high-power LPP-EUV light source with unique debris mitigation system using a magnetic field [10809-57]

10809 1Q Debris-free high-brightness light source based on LPP for actinic EUV microscopy and metrology applications [10809-61]

POSTER SESSION: IMAGING/OPTICS

10809 is Lateral shearing interferometry for high-NA EUV wavefront metrology [10809-63]

10809 1T Reflectance measurement of EUV mirrors with s- and p-polarized light using polarization control units [10809-64]

10809 IU Spatially resolved reflectometry for EUV optical components [10809-65]

\section{POSTER SESSION: MATERIALS}

10809 1V Actinic tools for EUV resist characterization in research and production [10809-67]

10809 1W In-situ measurement of outgassing generated from EUV metal oxide nanoparticles resist during electron irradiation [10809-68]

10809 1X EUV sensitizer for resists and spin-on-carbon materials [10809-69]

10809 IY Development of absorption-coefficient-measurement method of EUV resist by direct-resist coating on a photodiode [10809-70]

POSTER SESSION: PROCESS CONTROL

$1080924 \quad$ Improvement of CD stability and defectivity in resist coating and developing process in EUV lithography process [10809-76] 
Proc. of SPIE Vol. 10809 1080901-6

Downloaded From: https://www.spiedigitallibrary.org/conference-proceedings-of-spie on 26 Apr 2023 Terms of Use: https://www.spiedigitallibrary.org/terms-of-use 


\title{
Authors
}

Numbers in the index correspond to the last two digits of the seven-digit citation identifier (CID) article numbering system used in Proceedings of SPIE. The first five digits reflect the volume number. Base 36 numbering is employed for the last two digits and indicates the order of articles within the volume. Numbers start with 00, 01, 02, 03, 04, 05, 06, 07, 08, 09, OA, OB...0Z, followed by 10-1Z, 20-2Z, etc.

\author{
Abe, Tamotsu, $1 \mathrm{M}$ \\ Abraham, Mathew, $1 \mathrm{~L}$ \\ Abramenko, Dimitri, $1 Q$ \\ Ahn, Jinho, OR \\ Anantha, Vidyasagar, 09 \\ Anderson, Chris, OV \\ Arps, J., 1E, 11 \\ Babulnath, Raghav, 09 \\ Bekaert, Joost, OM \\ Bergmann, K., IV \\ Biafore, John J., OA \\ Biermanns-Föth, A., 1E, 11 \\ Biesemans, S., ON \\ Biller, J., $1 \mathrm{~A}$ \\ Blanco, V., ON \\ Blankenship, David, OA \\ Brandt, David C., $1 \mathrm{~L}$ \\ Brose, S., 1A, IV \\ Brown, Daniel J., $1 \mathrm{~L}$ \\ Brunner, Timothy, 03,00 \\ Buchholz, Christian, $1 \mathrm{U}$ \\ Cerio, Frank, OF \\ Chae, Yoo-Jin, $1 \mathrm{H}$ \\ Chang, Yi-Hsin, $\mathrm{OC}$ \\ Chao, Alexander W., 07 \\ Chen, John Y., 02 \\ Chen, Lei, IS \\ Church, Jennifer, 16 \\ Cordova, Isvar A., OV \\ Cross, Andrew, 09 \\ Dang, Luong Nguyen, OX \\ Danylyuk, S., 1A, $1 \mathrm{~V}$ \\ De Bisschop, Peter, 09 \\ De Dea, Silvia, $1 \mathrm{~L}$ \\ De Poortere, E., ON \\ De Silva, Anuja, 16 \\ De Simone, Danilo, OU \\ Deuter, V., IA \\ Devasahayam, Adrian J., OF \\ Dillen, Harm, 0C \\ Dong, Lisong, 19 \\ Dusa, M., ON \\ Echigo, Masatoshi, $1 \mathrm{X}$ \\ Ekinci, Yasin, OX \\ Ellwi, Samir, 1Q \\ Enomoto, Masashi, 24 \\ Ershov, Alexander I., 1L \\ Fan, Taian, 19 \\ Felix, Nelson M., 16
}

Fischer, Andreas, $1 \mathrm{U}$

Fomenkov, Igor V., $1 \mathrm{~L}$

Foubert, Philippe, 24

Franke, J.-H., ON

Freychet, Guillaume, OV

Frommhold, Andreas, OM

Fung, Derek, 09

Gädda, Thomas, OX

Gargini, Paolo A., 14

Gillijns, W., ON

Glushkov, Denis, 1Q

Goldfarb, Dario L., 16

Graves, Trey, OA

Grochowicz, M., 1A

Grützmacher, D., 1A

Guo, Jing, 16

Gupta, Puneet, 1H

Halder, Sandip, 09

Harada, Tetsuo, IT, IY

Hashimoto, Yusaku, 24

Hendrickx, Eric, OM, ON

Hess, Alexander, 16

Hexemer, Alexander, OV

Hong, Juhee, OR

Hori, Tsukasa, IM

Hunsche, Stefan, OC

Ip, Vincent, OF

Ivanov, Vladimir, 1Q

Jang, Yongju, OR

Jonckheere, Rik, 1H

Juschkin, L., IA

Kadoi, M., IW

Kamei, Yuya, 24

Karaste, Kimmo, OX

Kawakami, Shinichiro, 24

Kawasuji, Yasufumi, $1 \mathrm{M}$

Kazizis, Kimmo, OX

Kea, Marc, OC

Kohli, Sandeep, OF

Kooiman, Marleen, OC

Koshelev, Konstantin, 1Q

Krivokorytov, Mikhail, 1Q

Krivtsun, Vladimir, 1Q

Kumar, Bharat, 16

Kumar, Dinesh, OV

LaForge, Andrew, $1 \mathrm{~L}$

Lash, Alexander, 1Q

Laubis, Christian, $1 U$

Laukkanen, Markus, OX 
Lebert, Rainer, 1E, 11, 1Q, 1V

Lee, Changhun, OR

Lee, Inhwan, OA

Lee, Meng H., OF

Lee, Sung-Gyu, $1 \mathrm{G}$

Legein, Colette, 05

Levinson, Harry J., 03

Levinson, Zac, 00

Levoso, Mathew S., OF

Lim, Mijung, OA

Long, Luke, $\mathrm{OB}$

Loosen, P., IV

Lyakhova, K., ON

Makinoshima, Takashi, $1 \mathrm{X}$

Mastenbroek, Marcel, 04

Matsumoto, Y., IW

McAfee, Terry, OV

Medvedev, Vyacheslav, $1 Q$

Meli, Luciana, 16

Mettry, Magi, 16

Minami, H., IW

Minami, Y., IW

Missalla, T., 1E, 1I, 1V

Miyakawa, Ryan, is

Mizoguchi, Hakaru, $1 \mathrm{M}$

Nafus, Kathleen, 0N, 24

Nagai, Shinji, $1 M$

Nakarai, Hiroaki, 1M

Nam, Keesoo, OR

Naulleau, Patrick, OB, OT, OV, IS

Neureuther, Andrew, OB, OT

Niihara, Shota, IY

Nishimura, Yuichi, $1 \mathrm{M}$

No, Hee-Ra, $1 G$

Oh, Hye-Keun, $1 G$

Oh, Se-Hun, IG

Pampfer, C., $1 \mathrm{E}$

Pandolfi, Ronald J., OV

Park, Chulkyun, OR

Phiesel, C., 1E, 1I, 1V

Piel, C., 1E, 11, 1V

Plihal, Martin, 09

Pollentier, Ivan, OU

Purvis, Michael A., $1 \mathrm{~L}$

Rafac, Robert J., $1 \mathrm{~L}$

Rajyaguru, Chirag, $1 \mathrm{~L}$

Ran, Xue, OU

Rantala, Juha, OX

Rio, D., ON

Rispens, Gijsbert, OC, OM

Robertson, Stewart A., OA

Rokitski, Slava, $1 \mathrm{~L}$

Rook, Katrina, OF

Sah, Kaushik, 09

Saito, Takashi, $1 \mathrm{M}$

Sato, Takashi, $1 \mathrm{X}$

Schafgans, Alexander A., $1 \mathrm{~L}$

Schiffelers, Guido, 05, OM

Scholze, Frank, $1 U$

Sekiguchi, A., IW
Seroglazov, Pavel, $1 Q$

Sherwin, Stuart, OT

Shimoaoki, Takeshi, 24

Shinjo, Sachiko, $1 \mathrm{X}$

Shiraishi, Yutaka, 1M

Sidelnikov, Yuri, 1Q

Smith, Bruce W., 00

Soltwisch, Victor, $1 \mathrm{U}$

Sonoda, Akihiro, 24

Soumagne, Georg, $1 \mathrm{M}$

Spence, C., ON

Srinivasan, Narasimhan, OF

Stewart, Jayson, $1 \mathrm{~L}$

Tadokoro, Masahide, 24

Tagbo, Claudia, $1 \mathrm{U}$

Takahashi, S., IW

Tang, Peng, OC

Tao, Yezheng, $1 \mathrm{~L}$

Taubner, T., 1A

Tien, Daniel, OC

Togashi, Yuta, $1 \mathrm{X}$

Toida, Takumi, $1 \mathrm{X}$

Ueno, Yoshifumi, 1M

Vaglio Pret, Alessandro, OA

Van Adrichem, P., ON

Van Look, Lieve, OM

Vandenberghe, Geert, OU

Vaschenko, Georgiy O., $1 \mathrm{~L}$

Venelderen, Pieter, OU

Verduijn, Erik, 00

Vesters, Yannick, OU

Vieker, J., IV

Vinokhodov, Alexander, 1Q

Wakana, Katsuhiko, $1 \mathrm{M}$

Wang, Cheng, OV

Wang, Fei, OC

Wang, Fuming, OC

Wang, Yanrong, 19

Watanabe, Takeo, 1T, 1W, $1 Y$

Wei, Yayi, 19

Wi, Seongju, OR

Wittebrood, Friso, 05

Wojtecki, Rudy J., 16

Wood, Obert, 00

Wu, Juhao, 07

Yabu, Takayuki, IM

Yakushev, Oleg, 1Q

Yakushkin, Alexey, 1Q

Yan, Jiang, 19

Yanagida, Tatsuya, 1M

Yang, Zhizhen, 19

Zhang, Jing, 19

Zhang, Pengcheng, OC

Zhu, Wenhua, is 


\title{
Conference Committee
}

\author{
Conference Chairs
}

Kurt G. Ronse, imec (Belgium)

Eric Hendrickx, imec (Belgium)

Patrick P. Naulleau, Lawrence Berkeley National Laboratory (United States)

Paolo A. Gargini, Stanford University (United States)

Toshiro Itani, EUVL Infrastructure Development Center, Inc. (Japan)

Conference Program Committee

Eric M. Panning, Intel Corporation (United States)

Winfried Kaiser, Carl Zeiss SMT GmbH (Germany)

Satoshi Tanaka, EUVL Infrastructure Development Center, Inc.

(Japan)

Session Chairs

1 Plenary Session

Patrick P. Naulleau, Lawrence Berkeley National Laboratory (United States)

Frank E. Abboud, Intel Corporation (United States)

2 EUV Scanner and Source

Chang-Moon Lim, SK Hynix, Inc. (Korea, Republic of)

Takayuki Uchiyama, EIDEC (Japan)

3 EUV Process Control

Anuja De Silva, IBM Corporation (United States)

Danilo De Simone, imec (Belgium)

4 EUV Mask Blanks: Joint Session with conferences 10809 and 10810

Takahiro Onove, HOYA Corporation (Japan)

Paul A. Morgan, Micron Technology, Inc. (United States)

5 EUV Materials I

Takahiro Kozawa, Osaka University (Japan)

Anna Lio, Intel Corporation (United States) 
6 EUV Mask and Imaging: Joint Session with conferences 10809 and 10810

Jo Finders, ASML Netherlands B.V. (Netherlands)

Ted Liang, Intel Corporation (United States)

$7 \quad$ EUV Inspection, Repair, and Verification: Joint Session with conferences 10809 and 10810

Yasin Ekinci, Paul Scherrer Institut (Switzerland)

Thomas Scherübl, Carl Zeiss SMT GmbH (Germany)

8 EUV Pellicle and Metrology: Joint Session with conferences 10809 and 10810

Naoya Hayashi, Dai Nippon Printing Company, Ltd. (Japan)

Byung Gook Kim, SAMSUNG Electronics Company, Ltd.

(Korea, Republic of)

9 EUV Materials II

Huixiong Dai, Applied Materials, Inc. (United States)

Toru Fujimori, FUJIFILM Corporation (Japan)

10 High-NA and Imaging

Lieve van Look, imec (Belgium)

Akiyoshi Suzuki, Gigaphoton Inc. (Japan

11 Patterning

Jan van Schoot, ASML Netherlands B.V. (Netherlands)

Eric M. Panning, Intel Corporation (United States) 


\section{Introduction}

The following papers are the manuscripts of the International Symposium on EUV lithography (EUVLS), organized by imec, Eureka, SPIE, and Eidec in Monterey (CA) from 17 to 20 September 2018.

The EUVL Symposium was for the second year co-organized together with Photomask 2018 Conference (PM) and was well attended. Over 580 attendees followed the sessions which were divided into joint sessions and separate sessions for EUVLS and PM.

After all the EUVL sessions, the EUVL Symposium Steering Committee jointly discussed the progress on the focus points identified in 2017 and formulated focus points towards 2019.

The Committee expressed strong confidence in EUVL insertion in 2019 at the $7 \mathrm{~nm}$ node. With EUVL source power increased to $250 \mathrm{~W}$ and the large number of scanner shipments in 2018, it is believed to be unlikely that EUVL will not be taken into (pilot) production in the next 12 months. The Committee also expressed the the opinion that the current status of photoresists and masks (including mask actinic infrastructure) is suitable to support 7-nm node insertion.

For the next technology nodes (5nm and beyond), attention in various areas is required. Focus item number one is still stochastics, leading to roughness and failures. Stochastics come partly from shot noise and partly from EUVL materials/processes and need to be co-optimized in order to guarantee the required yield. Focus item two is EUV mask defectivity, which commonly will be tackled by using EUV pellicles. The use of pellicles is still hard and troublesome and reduces the throughput. Focus item three is litho cluster reliability, which should exceed $90 \%$ (estimated nowadays to reach about $80 \%$ ). Downtime should primarily consist of scheduled down, no surprises. Finally, focus item four calls for the development of actinic patterned mask inspection and alternative mask absorbers to increase the overlapping process windows of typical use cases.

With these conclusions, the community is informed where to concentrate research and development efforts. The next EUVL Symposium is again planned in September 2019 in Monterey, again co-organized with the PM2019 Conference.

\section{Kurt G. Ronse \\ Eric Hendrickx \\ Patrick P. Naulleau \\ Paolo A. Gargini Toshiro Itani}


Proc. of SPIE Vol. 10809 1080901-12 Downloaded From: https://www.spiedigitallibrary.org/conference-proceedings-of-spie on 26 Apr 2023
Terms of Use: https://www.spiedigitallibrary.org/terms-of-use 